\title{
Mitigating micro- and macro-vascular complications of diabetes beginning in adolescence
}

\author{
This article was published in the following Dove Press journal: \\ Vascular Health and Risk Management \\ 17 November 2009 \\ Number of times this article has been viewed
}

\author{
Daniel J Moore' \\ Justin M Gregory ${ }^{2}$ \\ Yaa A Kumah-Crystal' \\ Jill H Simmons' \\ 'Department of Pediatrics, Division \\ of Endocrinology and Diabetes, \\ Vanderbilt Children's Hospital, \\ Nashville, TN, USA; ${ }^{2}$ Department \\ of Pediatrics, University \\ of Tennessee, Memphis, \\ TN, USA
}

\begin{abstract}
Diabetes is a chronic disorder, which manifests when insulin levels or resistance to insulin action becomes insufficient to control systemic glucose levels. Although the number of available agents to manage diabetes continues to expand rapidly, the maintenance of euglycemia by individuals with diabetes remains a substantial challenge. Unfortunately, many patients with type 1 and type 2 diabetes will ultimately experience diabetes complications. These complications result from the toxic effects of chronic hyperglycemia combined with other metabolic derangements that afflict persons with diabetes. This review will present a comprehensive look at the complications of diabetes, the risk factors for their progression, the mechanistic basis for their development, and the clinical approach to screening for, preventing, and treating these sequelae. In addition, since diabetes is commonly diagnosed in childhood, we will provide a special focus on the care of the adolescent patient.
\end{abstract}

Keywords: diabetes, microvascular, macrovascular, complications, glycemia, pediatric, retinopathy, nephropathy, neuropathy

\section{Introduction}

Diabetes describes a collection of chronic disorders in which insulin production is insufficient to maintain normal glucose homeostasis. Whether insulin insufficiency is due to loss of pancreatic islet beta cells or resistance to insulin action, the end result is chronic elevation of systemic glucose levels. Trials such as the Diabetes Control and Complications Trial (for type 1 diabetes) ${ }^{1}$ or the UK Prospective Diabetes Study (for type 2 diabetes) ${ }^{2}$ have demonstrated the benefits of intensive management on long-term disease complications. However, the implementation of intensive management strategies has remained a challenge particularly with the increasing number of patients with diabetes worldwide, and many patients struggle to maintain euglycemia. In addition, emerging evidence suggests that in some circumstances, intensive glucose control alone may be insufficient to completely prevent the complications associated with diabetes.

For type 1 diabetes (T1DM), there is likely to be a window between initial diagnosis and the onset of diabetes complications. The case is more challenging in the setting of type 2 diabetes (T2DM) where organ damage may exist at the time of initial presentation. While there are methods to manage diabetes complications, these complications are generally progressive and often become irreversible; thus, mitigating the risk for their appearance and identifying and treating them early is of utmost importance for clinicians and patients. While T1DM remains the predominant
Correspondence: Jill H Simmons of Endocrinology and Diabetes, Vanderbilt Children's Hospital, I I I36 Doctor's Office Tower, 2200 Children's Way, Nashville, TN 37232-9170, USA Tel + I 6I5-322-7427

Fax + I 615-343-5845

Email jill.h.simmons@vanderbilt.edu 
diagnosis in childhood, the number of cases of T2DM continues to rise, and thus anticipation and intervention for all forms of diabetes is becoming a primary role of the pediatric endocrine provider. In this review, we will address 1) the risk factors that predict micro- and macro-vascular complications, 2) the basic mechanisms by which these risk factors are translated into tissue injury, and 3) how clinical and scientific data can be used to direct a rational approach to therapeutic interventions. Throughout, we will provide an additional focus on the pediatric patient and consider how best to set the stage in childhood to empower patients to prevent complications throughout their lives.

\section{Clinical overview of vascular disease in diabetes}

It has long been appreciated that persons with diabetes are at substantial risk for tissue injury in organs supplied by an endarterial system due to microangiopathy. These microvascular complications, which include nephropathy, retinopathy, and neuropathy, have even served as end-points in numerous large studies of diabetes control and its benefits. As the management of diabetes and these complications has improved, it has become more apparent that there are additional factors that limit the quality and length of life of patients with diabetes. Indeed, there is substantial emerging evidence that these patients are also at risk for macrovascular disease including heart disease and stroke. In this section we will consider the epidemiology of these complications and the clinical risk factors that may predict their progression.

\section{Epidemiology of vascular disease in patients with diabetes}

In the pediatric population, T1DM has historically been more prevalent than T2DM, with an incidence of approximately 24 per 100,000 people. T2DM is becoming more common in concert with increasing rates of childhood obesity. Incidence rates of T2DM have been reported between 17 and 49 per 100,000 , with most new pediatric diagnoses documented among 15- to 19-year-old minority groups. ${ }^{3}$ The eventual metabolic and vascular consequences of T1DM and T2DM are essentially the same. The microvascular complications associated with diabetes mellitus, which include nephropathy, retinopathy, and neuropathy, lead to the sequelae commonly associated with diabetes such as renal failure, blindness, and distal extremity amputations. These complications greatly affect the quality of life for patients with diabetes, and they also contribute to a decreased life expectancy by an average of 5 to 10 years. ${ }^{4}$ In the following sections, we will review the clinical presentation of the range of vascular complications of diabetes.

\section{Nephropathy}

Diabetic nephropathy is a condition that can lead to end stage renal disease requiring dialysis and eventual transplant. Patients may initially develop microalbuminuria that can develop into gross proteinuria. Gross proteinuria is an indication of widespread microvascular disease. These patients also develop elevated blood pressures and decreased glomerular filtration, eventually leading to renal failure. In the past, diabetic nephropathy has been reported to develop in about $40 \%$ of patients with T1DM and about $20 \%$ of patients with T2DM. ${ }^{5}$ With improved diabetes care, the incidence of reported diabetic nephropathy is now about $15 \%$ to $20 \%$ in T1DM and T2DM. In adults with T1DM, clinical findings of diabetic nephropathy (microalbuminuria) can appear as early as 5 years after onset, which can eventually lead to gross proteinuria after an average of about 17 years of disease. ${ }^{5}$ End stage renal disease develops after an average of about 23 years of T1DM. ${ }^{5}$ The timeline is more difficult to quantify in T2DM, as onset of disease may be uncertain. The risk of developing nephropathy in T1DM decreases after about 25 years if a patient has not developed gross proteinuria. In pediatrics, microalbuminuria can be seen shortly after disease onset in $25 \%$ to $50 \%$ of patients. This initial microalbuminuria is usually reversible with insulin administration and is not associated with histological lesions of the filtration system. Progression to overt proteinuria is rare in childhood and is seen in just $1 \%$ to $1.5 \%$ of pediatric patients. ${ }^{6}$ After about 5 years, as in the adult population, susceptible patients will develop more concerning microalbuminuria associated with changes of the filtration system such as glomerular basement membrane thickening and mesangial expansion. ${ }^{6}$ About 7 to 10 years after diagnosis, one-third of patients will develop microalbuminuria. One-fifth will develop gross proteinuria, which will progress to end stage renal disease after 5 to 10 years. $^{6}$

\section{Retinopathy}

Retinopathy is the result of macrovascular occlusion and microvascular leakage into the retina. Diabetic retinopathy is a vision-threatening process that leads to almost 10,000 new cases of blindness in the US each year. It is the leading cause of blindness between the ages of 25 to 74 years, and is responsible for about $12 \%$ of blindness in the US. ${ }^{7}$ It is reported in the T1DM population that children have 
a negligible risk of developing retinopathy during the first decade of life, even when diagnosed prior to age two years. ${ }^{8}$ In adults after seven years of T1DM, about $50 \%$ of patients have some degree of retinopathy; while after twenty years, approximately $90 \%$ demonstrate retinopathy. ${ }^{7}$

\section{Neuropathy}

Diabetic neuropathy is the result of slowed motor and sensory nerve conduction that most commonly develops between 5 and 10 years after onset of disease. ${ }^{4}$ Neuropathy can present as peripheral sensorimotor, cranial, peripheral motor, and autonomic neuropathy. The peripheral sensorimotor neuropathy is symmetric and mostly affects the feet, leading to diminished sensation and paresthesia. Diminished sensation can cause altered perception of foot pressures and altered foot architecture. This change can result in injury, non-healing wounds, and eventual amputations. Alternatively, diabetic neuropathy can lead to painful and debilitating hypersensation and burning dysesthesias, which makes ambulation difficult. ${ }^{4}$ The prevalence of peripheral neuropathy in the pediatric population has been reported to range between $7 \%$ to $57 \%$ depending on the diagnostic criteria used, with subclinical neuropathy reported to occur in $57 \%$ of children and adolescents with T1DM. ${ }^{9}$ On average, about $50 \%$ of patients with diabetes will develop neuropathy. ${ }^{9}$ As prevalence is based on disease duration, the majority of affected patients will be those who were diagnosed in childhood.

\section{Macrovascular disease}

While microvascular disease contributes significantly to morbidity as well as to mortality in patients with diabetes, macrovascular complications are likely to be equally important determinants of life-span and quality of life. Macrovascular complications include coronary artery disease, stroke, and peripheral vascular disease. By the 1970s and 1980s, atherosclerotic disease had been recognized as one of the foremost complications of diabetes. ${ }^{10-13}$ While over the past 30 years the majority of studies of macrovascular disease have focused on the T2DM population, more recent studies specifically examining the T1DM population are now available. The Diabetes UK Cohort Study ${ }^{14}$ followed a cohort of over 23,000 patients with T1DM for an average of 17 years per subject. This study demonstrated statistically significant higher standardized mortality ratios (SMR, ie, the ratio of observed deaths to expected deaths in a standard population) from heart disease across all age groups and genders for patients with T1DM compared with the corresponding general population. ${ }^{14}$ Across all age groups in the study, men with T1DM carried a SMR of 4.5 for ischemic heart disease while women with T1DM had a SMR of 8.8. These data also showed higher incidence of cardiovascular mortality in younger adults with T1DM, particularly a staggeringly high SMR for women with T1DM under age 39. Women had an SMR of 44.8 in the 3rd decade of life and 41.6 in the 4 th decade, indicating a loss of cardioprotection seen in young women without diabetes. Increased mortality rates across age groups from stroke were similarly observed. ${ }^{10}$

In addition to having higher morbidity and mortality from macrovascular disease, patients with T1DM are thought to have atherosclerotic changes at an earlier age. Studies by Jarvisalo et al and Krantz et al evaluated carotid intima media thickness (IMT), a sensitive marker for coronary and cerebral vascular disease, in children, adolescents, and young adults with T1DM. ${ }^{15-18}$ Carotid IMT was found to be significantly greater in patients with T1DM than their age-matched, unaffected counterparts.

\section{Risk factors for the development of vascular complications}

The complications of diabetes are numerous and ultimately affect a large proportion of patients with the disease. Efforts to prevent these complications are aided by numerous studies that have uncovered contributing risk factors to the susceptibility to, and progression of, organ damage. The preponderance of evidence suggests a highly influential role of blood glucose levels in modifying the risk for these processes, particularly the vascular complications. In addition, there are several additional, modifiable parameters unrelated to glycemic control that may play key roles in the development of vascular complications.

\section{Role of glycemic factors: hyperglycemia as the culprit}

Hyperglycemia plays an important role in the microvascular and macrovascular complications of diabetes. The Diabetes Control and Complications Trial (DCCT), which studied patients with T1DM, demonstrated a significant reduction of microvascular complications from diabetes through the reduction of participants' glycosylated hemoglobin $\left(\mathrm{HbA}_{1 \mathrm{c}}\right)$. Lowering $\mathrm{HbA}_{1 \mathrm{c}}$ from $8.0 \%$ to $7.2 \%$ reduced microvascular complications by as much as $34 \%$ to $76 \%{ }^{1}$ The United Kingdom Prospective Diabetes Study (UKPDS), which examined patients with T2DM, also helped to demonstrate the benefits of intensive blood-glucose control by showing that a reduction 
of $\mathrm{HbA}_{1 \mathrm{c}}$ levels by $1 \%$ could decrease microvascular complications of diabetes by approximately $25 \%{ }^{2}$

The DCCT also demonstrated that glycemic control could also reduce the risk of diabetic nephropathy in pediatric patients. In the DCCT, patients were divided into two groups treated either with intensive insulin therapy or conventional therapy to determine whether intensive therapy could delay the development of complications. To ascertain whether intensive therapy could slow the progress of preexisting complications, patients were further subdivided into a primary prevention cohort, who had no complications at baseline, and a secondary intervention cohort, who had some evidence of complications at baseline. These patients had mild to moderate retinopathy and urine albumin excretion under $200 \mathrm{mg}$ per 24 hours. In the adolescent subgroup of the DCCT, which included patients aged 13 to 17 years, there was a $10 \%$ risk reduction in the development of microalbuminuria in the group that received intensive insulin management as compared to the conventionally treated group in the primary prevention cohort. In the secondary intervention cohort, the risk of developing microalbuminuria was decreased by $55 \%$ in the group that underwent intensive insulin management as compared to the conventionally treated group. ${ }^{6}$ In the full evaluation of all patients age 13 to 29 , the risk of nephropathy was decreased by $35 \%$ in the primary prevention cohort and $45 \%$ in the secondary intervention cohort (Figure 1). ${ }^{19}$

Optimizing glycemic control of pediatric patients was also shown to improve outcomes of retinopathy in the DCCT. ${ }^{1}$ In the adolescent group age 13 to 17 years old, the patients in the aggressive glucose management group had a $53 \%$ decrease in risk of initially developing retinopathy (in the primary prevention cohort). The risk of progression of retinopathy was decreased by $70 \%$ in the secondary intervention cohort. ${ }^{1,20}$ In those patients 13 to 29 years old, the risk of retinopathy was decreased by $75 \%$ in the primary prevention cohort and 55\% in the secondary intervention cohort. $^{19}$

The DCCT further demonstrated positive effects of intensive insulin therapy on the prevention of diabetic neuropathy ${ }^{1}$. Rigorous metabolic control decreased the prevalence of symptomatic, electrophysiologic, and autonomic indicators of neuropathy by $38 \%$ to $59 \%$. After 5 years of treatment with intensive insulin therapy, evidence

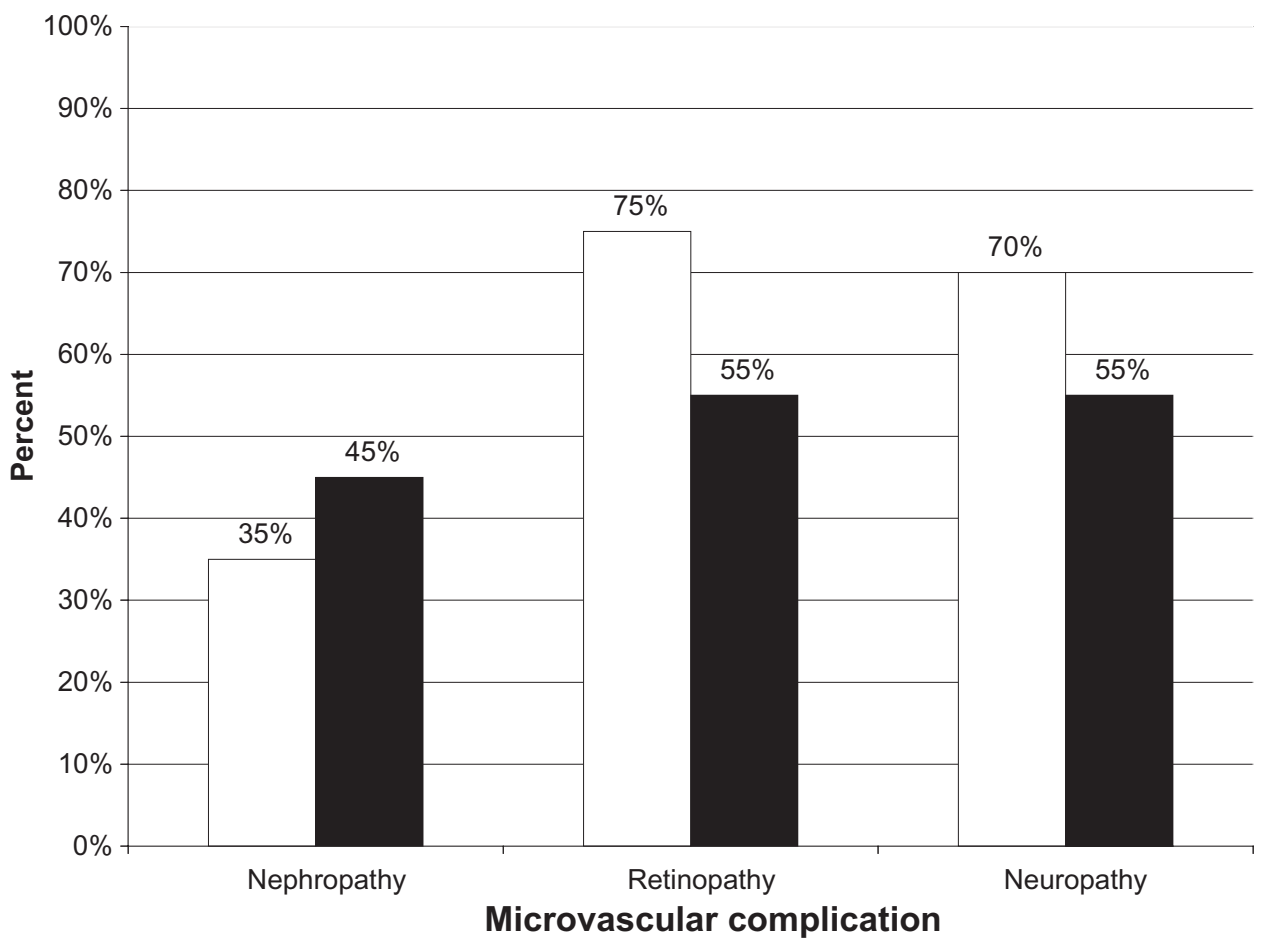

$\square$ Primary prevention cohort $\square$ Secondary intervention cohort

Figure I The Diabetes Control and Complications Trial: percent reduction of microvascular complication with intensive therapy. Patients age I3 to 39 with TIDM were divided into two cohorts, primary prevention cohort (no complications), and secondary intervention cohort (mild to moderate retinopathy, urine microalbumin $<200 \mathrm{mg} / 24 \mathrm{~h}$ ). The patients who underwent intensive therapy with insulin showed significant reduction of microvascular complications in both cohorts. Drawn from data of Skyler JS. Diabetic complications. The importance of glucose control. Endocrinol Metab Clin North Am. 1996;25(2):243-254. ${ }^{19}$ 
of neuropathy was reduced by $50 \%$. In the primary prevention cohort, only $3 \%$ of patients treated with intensive therapy versus $10 \%$ of patients treated with conventional therapy showed signs of diabetic neuropathy. In the secondary cohort, evidence of clinical neuropathy was seen in only $7 \%$ of patients treated with intensive therapy versus $16 \%$ of patients treated with conventional therapy. ${ }^{9}$ Overall, the neuropathy was decreased by $70 \%$ in the primary prevention cohort and $55 \%$ in the secondary intervention cohort. ${ }^{19}$ Specific data restricted to the pediatric population have not been available.

There is also strong data from UKPDS on glycemic control in preventing microvascular complications in patients with T2DM. ${ }^{2}$ The combined risk of vitreous hemorrhage, need for photocoagulation and renal failure was decreased by $25 \%$ by reducing $\mathrm{HbA}_{1 \mathrm{c}}$ from $7.9 \%$ to $7.0 \%$. As the patients enrolled in the UKPDS study were between the ages of 25 and 65, there are no specific data from the study about glycemic control in pediatric patients with T2DM, although the importance of proper glycemic control is strongly suggested by the available adult data.

The observational Epidemiology of Diabetes Interventions and Complications (EDIC) study provides additional evidence that indicates intensive therapy has long-term benefits in preventing macrovascular disease in T1DM patients. Of the 1441 patients aged 13 to 40 who had been randomly assigned to intensive or conventional insulin therapy during a mean of 6.5 years in the DCCT study, 97\% enrolled in the EDIC at the completion of the DCCT study in 1993. The conventional treatment group was offered intensive treatment and the difference in mean $\mathrm{HbA}_{1 \mathrm{c}}$, which was initially $7.4 \%$ in the intensive treatment group and $9.1 \%$ in the conventional group, narrowed at the end of the 11-year follow up to a non-significant difference of $7.9 \%$ and $7.8 \%$ in the intensive and conventional treatment groups, respectively.

A report from EDIC showed a relationship between glycemia and carotid artery IMT. At year 1 of EDIC, carotid IMT was similar to the age and sex-matched non-diabetic population, but at year 6 the thickness was significantly greater in the patients with diabetes compared with the controls. Additionally, after adjustment for sex, age, instrumentation, and year 1 IMT, a statistically significant difference in the mean progression of the common carotid artery IMT was observed: $0.032 \mathrm{~mm}$ in the intensive treatment group compared to $0.046 \mathrm{~mm}$ in the conventional therapy groups. ${ }^{21}$

A second report from EDIC further examined cardiovascular disease after an average of 17 years of follow up. In that assessment, 46 cardiovascular disease events occurred in 31 patients in the DCCT intensive treatment group compared to 98 events in 52 patients in the conventional group, representing a $42 \%$ reduction in any cardiovascular event. The risk of nonfatal myocardial infarction, stroke, or death from cardiovascular disease was reduced by $57 \%$ with intensive treatment. ${ }^{22}$ These data from EDIC support the argument that early implementation of intensive therapy reduces future incidence of cardiovascular disease. Because there was no difference in glycemia as measured by $\mathrm{HbA}_{1 \mathrm{c}}$ at the end of the study, these findings support the notion that long-lasting and fundamental vascular changes can occur early in the course of an illness as a result of hyperglycemia. This observation has been described as the "imprinting" theory of glycemic control.

Additional studies have supported the findings from EDIC. The Wisconsin Epidemiologic Study of Diabetic Retinopathy (WESDR) examined a cohort of 879 individuals with T1DM free of cardiovascular disease and end-stage renal disease at baseline. At the end of 20 years, elevated $\mathrm{HbA}_{1 \mathrm{c}}$ was associated with both all-cause and cardiovascular mortality independent of the duration of diabetes, smoking, hypertension, and proteinuria. ${ }^{23} \mathrm{~A}$ meta-analysis of 3 T1DM and 10 T2DM observational studies suggested chronic hyperglycemia was associated with an increased risk for cardiovascular disease. ${ }^{24}$ In the prospective Pittsburgh Epidemiology of Diabetes Complications study (PEDC), glycemia was noted to be a powerful predictor of symptomatic lower extremity arterial disease. ${ }^{25}$

\section{Role of non-glycemic factors: when hyperglycemia is not the culprit}

Although in patients with diabetes it is attractive to postulate hyperglycemia as the ultimate cause of pathology, diabetes is a multi-factorial process. There have been studies that have not substantiated a relationship between hyperglycemia alone and some vascular complications. These studies suggest that vascular injury can also result from non-glycemic factors. In the case of the microvascular complications of diabetes such as nephropathy, retinopathy and neuropathy, the major non-glycemic factors include hypertension, smoking, and obesity. In the pediatric population, puberty may play an additional role as a non-modifiable risk factor. ${ }^{6,8,9}$

In coronary artery disease, the macrovascular complication most rigorously studied, there is also evidence that suggests contributions from non-glycemic risk factors. Reports from two prospective T1DM cohort studies, PEDC and EURODIAB, suggested that hyperglycemia was not an 
independent predictor of coronary artery disease. ${ }^{26-28}$ The Freemantle Diabetes Study found no link between glycemic control and cerebrovascular events in T1DM. ${ }^{29}$ In 1995 , a DCCT Research Group report compared the number of macrovascular events between T1DM patients treated with intensive insulin therapy versus conventional therapy. While a $42 \%$ reduction in macrovascular complications with intensive treatment was observed at the study's completion, it did not achieve statistical significance, likely due to the patients' young age at baseline and the exclusion of those with risk factors for macrovascular disease at baseline. ${ }^{30}$ In macrovascular disease, hypertension, smoking, obesity, puberty, and dyslipidemia all play roles as modifiable non-glycemic risk factors.

\section{Hypertension}

Persistently elevated blood pressures in patients with diabetes can have severe complications on both the micro- and macrovascular level. Patients with T2DM often have several risk factors for elevated blood pressures, such as obesity, family history, and generally poor cardiovascular health. The onset of hypertension in T2DM is usually difficult to pinpoint due to the uncertainty of disease onset. In patient populations with T1DM, however, in which onset of disease is more certain and there are less confounding alternate risk factors, the initiation of, and trend towards, hypertension is easier to track.

As the regulation of blood pressure is interconnected to the renal system, the onset of renal pathology seen in diabetes is usually noted around the time when blood pressure elevations begin. In diabetic nephropathy, patients will initially develop microalbuminuria. Gross proteinuria follows and is an indication of widespread microvascular disease. As this glomerular damage occurs, patients develop trends of elevated blood pressures.

There is some question about when elevated blood pressures appear in the progression of diabetic nephropathy whether microalbuminuria precedes it, occurs concurrently, or is a secondary effect. Patients with T2DM usually have some degree of hypertension at presentation with microalbuminuria. ${ }^{31}$ It is generally noted that patients with T1DM have normal in-office blood pressure readings until microalbuminuria is detected. This experience leads to the general conclusion that microalbuminuria precedes hypertension. However, it has also been shown that increases in systolic blood pressure during sleep can precede the onset of microalbuminuria in patients with $\mathrm{T} 1 \mathrm{DM},{ }^{31}$ raising questions about the actual mechanism of cause and effect that will need to be further elucidated. Once evidence of hypertension and nephropathy are both present in patients with diabetes, these patients are ultimately at risk of developing renal failure and end stage renal disease. ${ }^{32}$

Hypertension also plays a key role in the pathology of diabetic retinopathy. The UKPDS Group demonstrated that in patients with T2DM, blood pressure control could delay the progression of retinopathy. ${ }^{33}$ Testa et al demonstrated that patients with T1DM who had blood pressures at the upper end of the normal range were likely to have progressive retinopathy. ${ }^{34}$ In another study by Chase et al in patients with T1DM, mildly elevated systolic and diastolic blood pressure ranges above the 90 th percentile but less than 141/90 $\mathrm{mmHg}$ were correlated with the presence of retinopathy. ${ }^{35}$

There is evidence that hypertension is an independent risk factor that can impact the development of diabetic neuropathy. A study of the risk factors for distal symmetrical polyneuropathy (DSP) found that hypertension showed the greatest impact in the development of DSP for individuals with diabetes of long and short duration. ${ }^{36}$ In the Pittsburgh cohort of T1DM, hypertension was associated with a 4-fold risk of developing DSP over 6 years, and it was found to be the single strongest predictor. ${ }^{37}$ The EURODIAB prospective study also demonstrated systolic blood pressure and other cardiac risk factors to be strong predictors of DSP, even after adjustment for age, duration of disease, and $\mathrm{HbA}_{1 \mathrm{c}}{ }^{38-40}$

\section{Smoking}

Smoking data, available in the DVP Wiss database based on self-reported smoking habits in patients with diabetes, show that more than $5 \%$ of 11 - to 15 -year-old school children with T1DM reported smoking, and up to $30 \%$ of adolescents aged 15 to 20 years smoke. ${ }^{41}$ In patients with diabetes, smoking can lead to increased risk of developing microvascular and macrovascular complications. A study by Hofer et al further showed that smoking may increase the risk of complications from T1DM, as smokers demonstrated a significantly higher $\mathrm{HbA}_{1 \mathrm{c}}$ than non-smokers. ${ }^{41}$ The CARDIA study showed a higher risk of abnormal glucose tolerance in young adults who smoke and in ex-smokers, as compared to persons who had never smoked. ${ }^{42}$ Chiodera et al found that smoking induces abnormal secretion of pituitary and counterregulatory hormones. ${ }^{43}$ Smoking can also lead to endothelial dysfunction, pathologic changes in low-density lipoprotein (LDL) cholesterol, platelet adherence, and inflammation of blood vessels. ${ }^{41}$

Smokers with T1DM have higher rates of microalbuminuria than non-smokers. Adverse effects are seen in retinopathy 
due to the reduction of retinal blood flow and retinal oxygen delivery. A study by Sinha et al following 100 patients over 6 years demonstrated that retinopathy was twice as prevalent in smokers as non-smokers. ${ }^{44}$ Smoking has been consistently associated with coronary artery disease ${ }^{21,22,27}$ and, not unexpectedly, a smoking-associated increase of cardiovascular risk in childhood T1DM has been reported. ${ }^{41}$

\section{Dyslipidemia}

Multiple studies in the T1DM population have implicated dyslipidemia as an independent risk factor for coronary artery disease. ${ }^{21,22}$ However, a PEDC report noted that HDL and triglyceride levels lacked predictive power for lower extremity arterial disease events. ${ }^{25}$ EDIC showed that progression of carotid IMT was associated with the ratio of LDL cholesterol to high-density lipoprotein (HDL) cholesterol; ${ }^{21}$ higher total cholesterol and LDL were independently associated with cardiovascular disease. ${ }^{22}$ Jarvisalo et al found that while having T1DM is an independent risk factor for increased carotid IMT in children, independent correlates for IMT also included LDL cholesterol and elevated systolic blood pressure. $^{16}$

In one observational study of patients younger than age $21,15.4 \%$ of patients with T1DM had total cholesterol (TC) levels greater than $200 \mathrm{mg} / \mathrm{dL}$ compared to $11.2 \%$ of age-matched control subjects from the National Health and Nutrition Examination Survey 2001-2002. ${ }^{45}$ The study also found a significant relationship between $\mathrm{HbA}_{1 \mathrm{c}}$ and TC as well as $\mathrm{HbA}_{1 \mathrm{c}}$ and non-HDL cholesterol, suggesting poor glucose control is often associated with dyslipidemia.

\section{Obesity}

It is well understood that obesity in children can have metabolic complications including insulin resistance and a general risk factor for developing T2DM. ${ }^{46}$ Even in the T1DM population, despite initial weight loss, obesity is becoming more prevalent. ${ }^{47}$ As obesity is associated with hypertension and dyslipidemia, a patient's poor nutritional status can exacerbate the risk of developing vascular complications of diabetes. ${ }^{48}$ Body mass index has been independently related to the development of cardiovascular disease. ${ }^{22}$

\section{Puberty}

There is evidence that puberty itself may be a risk factor for the development of vascular complications. This conclusion is based on the observations that despite disease duration, the majority of the complications initially present or become more significant after the onset of puberty.
Puberty is associated with worsening microalbuminuria and progression of diabetic nephropathy. Microalbuminuria is rare before puberty. An extended pre-pubertal duration appears to prolong the time to development of microalbuminuria. However, the pre-pubertal duration of diabetes can be counted as a contributing factor for microalbuminuria after the onset of puberty. Pubertal factors are thought to accelerate the development and progression of microalbuminuria. These factors include worsening of compliance with treatment during adolescence, increases in blood pressure, and production of sex steroids influencing the effects of hyperglycemia. There are very likely many other unidentified pubertal factors that contribute to the effects on diabetic nephropathy. ${ }^{6}$

Within the first decade of life, children are at minimal risk for retinopathy and ocular complications from diabetes. ${ }^{8}$ A study by Rogers et al of diabetic retinopathy in children demonstrated that despite similar $\mathrm{HbA}_{\mathrm{lc}}$ and duration of disease, pre-pubertal patients had a lower degree of retinopathy than patients in late puberty. ${ }^{49}$ Klein et al followed 996 patients with T1DM diagnosed before age $30 .^{50}$ The study was able to identify only one patient between ages 10 to 14 who had evidence of moderate retinopathy, and just one patient under age 10 who had evidence of mild retinopathy. Additionally, none of the patients at those ages had retinopathy to a degree that would have required any treatment.

Like other microvascular complications of diabetes, symptomatic diabetic polyneuropathy is rarely seen in young children, with increased signs and symptoms during adolescence. A study of puberty and diabetic nephropathy by Riihimaa et al evaluated peripheral nerve function in 100 preand post-pubertal children with T1DM (age $>9$ years and diabetes duration $>2$ years) and age- and sex-matched healthy control subjects. ${ }^{51}$ This study found increasing subclinical motor nerve impairment during late puberty and after puberty. They concluded that poor metabolic control during puberty due to hormonal changes, and likely poor motivation, was the leading cause of peripheral nerve function deterioration in patients with T1DM.

\section{Microvascular disease as a risk factor}

Interestingly, microvascular disease itself conferred an independent risk for macrovascular disease. The results of the DCCT suggested that reducing microalbuminuria and autonomic neuropathy could be beneficial in reducing macrovascular disease.$^{30}$ EDIC demonstrated that microalbuminuria predicted progression of IMT and risk of cardiovascular disease. ${ }^{21,22}$ Renal disease has been shown to be a powerful 
predictor of coronary artery disease and peripheral vascular disease. $^{25,27}$

\section{Role of genetic factors}

Many of the risk factors discussed above may themselves be modified by heritable traits in addition to environmental influences. As such, the role of genetic factors is receiving emerging attention. Identification of susceptibility genes may provide greater understanding of the mechanism of these events. To date, investigation into genetic determinants and susceptibility to diabetic complications has focused primarily on diabetic nephropathy and premature coronary artery disease.

In diabetic nephropathy, there is a general observation that a peak incidence occurs during the second decade of life followed by a decline. This observation leads to the postulate that there are subsets of individuals who are susceptible to the development of nephropathy during that period as compared to those who never go on to develop nephropathy. Studies of sibling pairs have shown familial aggregation of diabetic nephropathy, where there is an occurrence in more members of a family than can be readily accounted for by chance. This association provides presumptive evidence of the operation of genetic factors. A cohort study by Quinn et al found that the cumulative risk of diabetic nephropathy after 30 years of diabetes was $71.5 \%$ in siblings of index cases with nephropathy as compared to $25.4 \%$ in siblings of index cases without nephropathy. ${ }^{52}$ Parent-offspring pairs and extended family studies have also been able to detect similar familial aggregation of diabetic nephropathy. ${ }^{53,54}$

There have also been family studies that show increased risk of premature coronary artery disease in family members of patients with diabetes who develop these complications. It is well established that first-degree relatives of individuals with coronary artery disease have an increased risk of death themselves from coronary artery disease. A study by Wagenknecht et al evaluated how the role of genetic factors contributed to atherosclerosis by measuring coronary artery calcification and evaluating the extent of familial aggregation. ${ }^{55}$ The study, which involved 122 individuals with T2DM (mean age 60 years) and 13 individuals without diabetes in 56 families, found that there were strong independent genetic factors that contributed to the variance of coronary artery calcification in T2DM.

Genome-wide linkage studies from affected or discordant sibling pairs have helped to identify some of the genes thought to be involved in increased susceptibility to diabetic nephropathy and premature coronary artery disease. Genes that are of particular interest include genes involved in the glucose-induced pathway such as paraxonase, an enzyme involved in detoxification of oxidation end products, and aldose reductase, an enzyme involved in the polyol pathway. Genes involved in the regulation of renal hemodynamics and in the reactivity of vascular cells such as endothelial nitric oxide synthase, and genes involved in lipid abnormalities such as ApoE are also under investigation. Based on data from linkage studies, the genes involved in diabetic nephropathy may be detected on chromosomes $3 \mathrm{q}, 7 \mathrm{q}, 9 \mathrm{q}$, and 20p. ${ }^{56}$ For coronary artery disease, the genes of interest may be on $2 \mathrm{q}, 3 \mathrm{q}$, and Xq. ${ }^{57}$ Work is being done to pinpoint the exact locations in these genes where modifications could be made to affect variance.

\section{Mechanism of vascular disease}

In addition to the clinical data identifying risk factors for vascular disease, there are also mechanistic data aimed at understanding how these risk factors can be translated at the cellular and molecular level into disease progression. These studies help to identify those risk factors that may play a direct role in vascular disease and also identify a number of targets that may be used to modify disease progression.

While the exact mechanism of micro- and macro-vascular damage is unclear, at least 3 distinct hyperglycemia-induced metabolic pathways appear to be involved in the pathogenesis of vascular complications: formation of advanced glycation end products (AGEs), activation of protein kinase $\mathrm{C}$ (PKC), and intracellular hyperglycemia creating disturbances in the polyol pathways. These pathways may provide areas of possible future medical intervention. In addition to the role of glucose metabolism, the renin-angiotensin system and the chronic inflammation that characterizes both T1DM and T2DM may also play a crucial role in vascular injury. An overview of these mechanisms is presented in Figure 2. Although an understanding of the mechanism of diabetes complications is valuable in appreciating approaches to diagnosis and intervention, several excellent reviews have considered the pathogenesis of diabetes complications and therefore we will not review them further here. ${ }^{58}$

\section{Screening}

Since the micro- and macrovascular complications of diabetes may readily become irreversible, it is critical for practitioners to detect these changes in patients at a stage where early interventions can minimize end-organ damage. Good screening tools should be sensitive and reproducible in a variety of circumstances. Practitioners should have the 


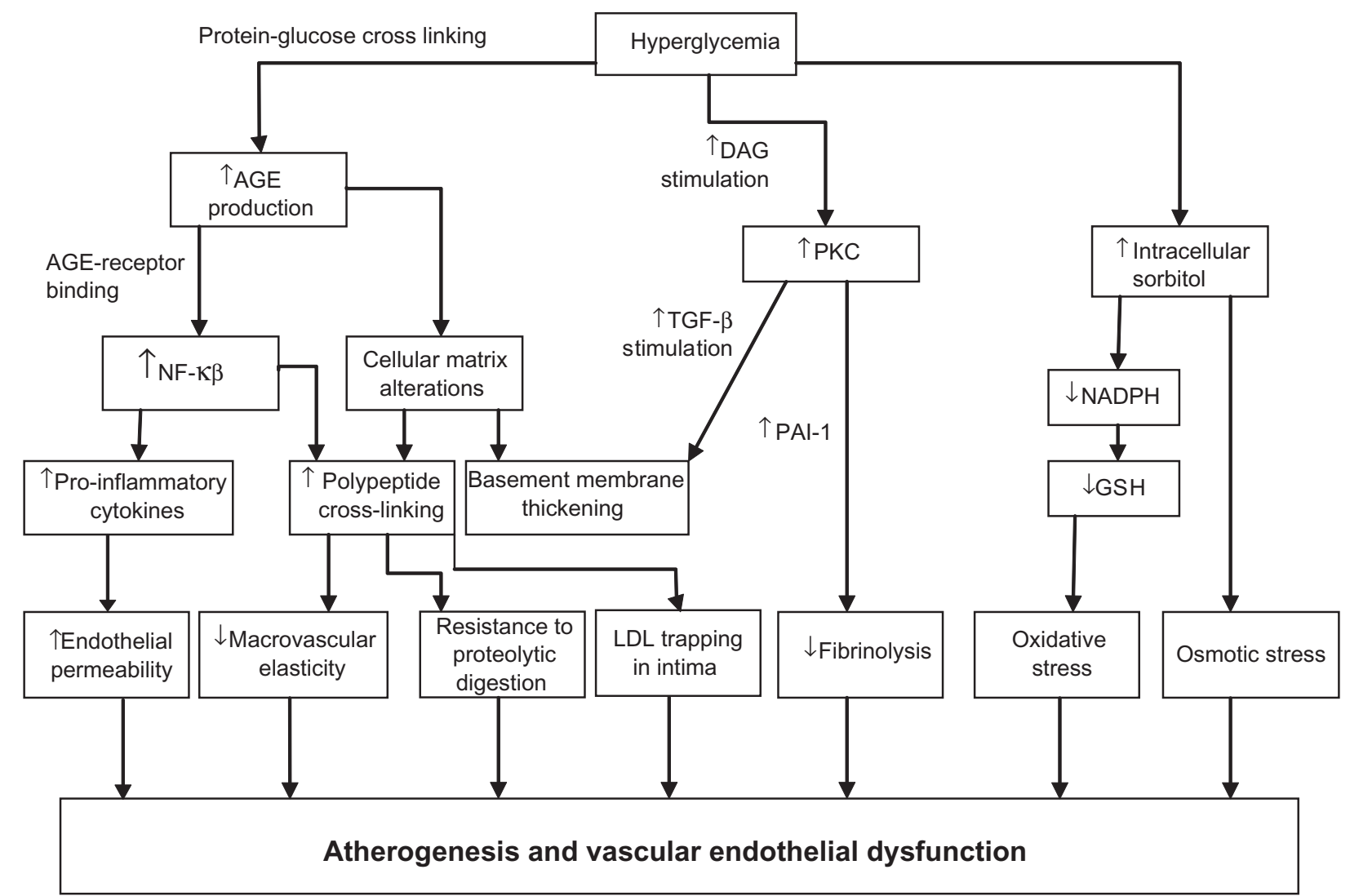

Figure 2 The contributions of hyperglycemia to vascular endothelial dysfunction and atherogenesis are mediated through several processes, including increased production of advanced glycation end products, activation of protein kinase $\mathrm{C}$ and sorbitol. These factors serve to enhance inflammatory processes including the activation of NF- $\kappa \beta$ and the production of pro-inflammatory cytokines. In turn, these factors cause injury to the vascular endothelium. This final common mechanism promotes atherogenesis and facilitates the vascular complications of diabetes.

Abbreviations: AGEs, advanced glycation end products; DAG, diacylglycerol; PKC, protein kinase C; LDL, low-density lipoprotein; GSH, glutathione; NADPH, nicotinamide adenine dinucleotide phosphate; NF- $\kappa \beta$, nuclear factor- $\kappa \beta$.

ability to target these screens to most high-risk individuals, when the consequence of missing the disease outweighs the cost and risk of intervention. Since many of the complications of diabetes develop several years after the onset of disease in the pediatric population, parameters defining age and circumstances to initiate screening are important to establish (summarized in Tables 1 to 5).

\section{Nephropathy}

Screening for nephropathy includes checking for microalbuminuria and proteinuria (Table 1). With microalbuminuria, patients lose between 30 and $300 \mathrm{mg}$ of albumin in 24 hours. The threshold of gross proteinuria is reached when patients lose over $300 \mathrm{mg}$ of albumin in 24 hours. Protein loss is greater than $500 \mathrm{mg}$ microalbuminuria per 24 hours in diabetic nephropathy. Spot urine proteins can also be measured. Early detection of protein loss can help physicians monitor a patient's progression to severe renal disease. In adults, nephropathy screening is performed annually in
T2DM starting at presentation; in T1DM, screening begins 5 years after onset of disease. ${ }^{59,60}$ In children with T1DM, screening depends upon whether the onset of diabetes is preor post-pubertal. Patients with pre-pubertal onset of diabetes should have screening 5 years after diabetes onset but not before age 9 years. In patients with pubertal/post-pubertal onset of diabetes, screening for nephropathy is initiated 2 years after diagnosis, and then performed annually. ${ }^{6}$ As with adult patients, where the onset of T2DM is more insidious, screening begins once diagnosed and annually thereafter.

\section{Retinopathy}

The development of retinopathy is strongly dependent upon the duration of diabetes. It is important that patients with diabetes have annual visits to an ophthalmologist to monitor for the progression of retinopathy, in order to prevent any irreversible vision loss (Table 2). The screening involves the assessment of visual acuity and a dilated eye exam to detect vascular changes in the retina. Pediatric patients with T1DM 
Table I Screening for nephropathy in pediatric diabetes

\begin{tabular}{|c|c|c|}
\hline \multirow[t]{4}{*}{ Screening tool } & \multicolumn{2}{|l|}{ 24-hour urine microalbumin } \\
\hline & \multicolumn{2}{|l|}{ Spot urine microalbumin } \\
\hline & \multicolumn{2}{|l|}{ Albumin/creatinine ratio in first morning void } \\
\hline & \multicolumn{2}{|l|}{ Timed overnight urine collection of albumin } \\
\hline \multirow[t]{5}{*}{ Screening parameters } & \multirow[t]{3}{*}{ Microalbuminuria } & $\begin{array}{l}\text { 24-hour urine sample, spot urine, or first } \\
\text { morning void: } \\
30-300 \mathrm{mg} \text { albumin/L }\end{array}$ \\
\hline & & $\begin{array}{l}\text { Timed overnight urine collection: } \\
20-200 \mu g / m i n \text { albumin }\end{array}$ \\
\hline & & $\begin{array}{l}\text { Albumin/creatinine ratio in spot urine: } \\
2.5-25 \mathrm{mg} / \mathrm{mmol} \text { (males) } \\
3.5-25 \mathrm{mg} / \mathrm{mmol} \text { (females) }\end{array}$ \\
\hline & Persistent/permanent microalbuminuria & $\begin{array}{l}\text { Meets above definitions for microalbuminuria } \\
\text { in a minimum of } 2 \text { out of } 3 \text { samples collected } \\
\text { consecutively (preferably within a 3- to } \\
\text { 6-month period) }\end{array}$ \\
\hline & Gross proteinuria & 24-hour albumin loss $>500 \mathrm{mg}$ \\
\hline \multirow[t]{2}{*}{ Age to initiate screening } & Type I diabetes mellitus & $\begin{array}{l}\text { If diabetes is diagnosed before puberty: } \\
\text { If diabetes is diagnosed before age } 4 \text {, begin } \\
\text { screening at age } 9 \\
\text { If diabetes is diagnosed between age 6-9, } \\
\text { begin screening at age II } \\
\text { If diabetes is diagnosed after age 10, begin } \\
\text { screening } 2 \text { years after diagnosis } \\
\text { If diabetes is diagnosed after puberty: } \\
\text { Initiate screening } 2 \text { years after diagnosis }\end{array}$ \\
\hline & Type 2 diabetes mellitus & Initiate screening at time of diagnosis \\
\hline Frequency of screening & $\begin{array}{l}\text { Screening is initially done in 6- } 12 \text {-month } \\
\text { intervals } \\
\text { With evidence of initial microalbuminuria: } \\
\text { Repeat testing is done over the next } \\
3-6 \text { months to confirm or exclude } \\
\text { persistent microalbuminuria }\end{array}$ & $\begin{array}{l}\text { With evidence of intermittent } \\
\text { microalbuminuria: Repeat testing is done } \\
\text { every month for the next } 3 \text { months } \\
\text { to confirm the presence of persistent } \\
\text { microalbuminuria }\end{array}$ \\
\hline
\end{tabular}

should begin screening 3 to 5 years after their diagnosis once they have turned 9 years of age according to the American Academy of Pediatrics (10 years of age per the American Academy of Ophthalmology). ${ }^{20}$ Since the risk of diabetic retinopathy is so small in patients under 9 years of age, they generally do not require prior screening regardless of the age of onset. Guidelines for pediatric patients with T2DM are less clearly defined but generally screening starts once diagnosed, as in adult populations..$^{59,60}$

\section{Neuropathy}

Screening for diabetic neuropathy includes checking for diminished sensory function and resultant injury (Table 3 ). These screens are performed with routine foot exams to evaluate for abrasions, ulcerations, and any evidence of Charcot arthropathy. To detect subclinical neuropathies and help track the progression of neuropathy, tools like the Semmes-Weinstein 10-g monofilament test are used to detect decreased pressure sensation to the feet. Tuning forks can be used to detect diminished vibratory sensation in the feet. Nerve conduction velocities measure the speed of a signal through a patient's nerves based on the degree of myelination and are considered the gold standard in testing for peripheral neuropathies. This modality is not as readily available in most outpatient clinical settings as the non-invasive tests, however. A study by Nelson et al raised concerns about the sensitivity of non-invasive screens in pediatric patients. ${ }^{61}$ The study examined 73 pediatric patients with T1DM with a mean age of 13 and duration of diabetes of at least 5 years. While subclinical evidence of diabetic neuropathy was detected in $42(57 \%)$ of these patients using nerve conductions studies, just 37 (50\%) were detected by vibration perception, 
Table 2 Screening for retinopathy in pediatric diabetes

\begin{tabular}{|c|c|c|}
\hline \multirow[t]{3}{*}{ Screening tool } & Visual acuity exam & Asses ability to focus and discern objects \\
\hline & Dilated eye exam & Detects vascular changes in the retina \\
\hline & Fundus photography and angiography & Quantifies degree of retinopathy \\
\hline \multirow[t]{3}{*}{ Screening parameters } & $\begin{array}{l}\text { Evidence of background nonproliferative } \\
\text { retinopathy }\end{array}$ & $\begin{array}{l}\text { Findings: Microaneurysms, dot and blot } \\
\text { hemorrhages, hard exudates }\end{array}$ \\
\hline & $\begin{array}{l}\text { Evidence of preproliferative retinopathy } \\
\text { and retinal ischemia }\end{array}$ & Findings: cotton wool spots \\
\hline & Evidence of proliferative retinopathy with & Findings: neovascularization of the optic disk \\
\hline \multirow[t]{2}{*}{ Age to initiate screening } & Type I diabetes mellitus & $\begin{array}{l}\text { Starting at age } 9 \text {, screen } 3-5 \text { years after } \\
\text { diagnosis }\end{array}$ \\
\hline & Type 2 diabetes mellitus & Starting at age 9 , screen at time of diagnosis \\
\hline Frequency of screening & Type I diabetes mellitus: annually & Type 2 diabetes mellitus: annually \\
\hline
\end{tabular}

$26(35 \%)$ were picked up by neurological exam and $19(26 \%)$ by tactile perception. Additionally, it was difficult to get full cooperation from very young children on the examinations that required feedback. The study questioned the utility of non-invasive testing in the pediatric population as a proper screening modality when compared with the gold standard of nerve conduction studies.

\section{Hypertension}

Because hypertension confers increased risk for the onset of microvascular complications and macrovascular complications later in adulthood, blood pressure monitoring and management is a key component of pediatric diabetes management (Table 4). Hypertension is defined in pediatric patients as an average systolic or diastolic blood pressure $\geq 95$ th percentile for age, sex, and height measured on 3 separate days; or a high-normal blood pressure with average systolic or diastolic blood pressure $\geq 90$ th but $<95$ th percentile for age, sex, and height measured on 3 separate days. ${ }^{62}$ Blood pressure should be assessed routinely at each clinical visit with other standard vital signs to monitor trends and detect elevations at an early stage. Obtaining 24-hour ambulatory blood pressure measurements can be useful in managing patients with persistently high clinical blood pressures before and after initiating antihypertensives. ${ }^{6}$ Discussing the family history of diabetes, hypertension, and the prevalent complications in a family can also provide clues to practitioners to guide decisions about management and interventions.

\section{Hyperlipidemia}

Dyslipidemia is also a critical but modifiable factor that should be considered in preventing or minimizing macrovascular disease. Although it is rare to see overt signs of atherosclerosis in pediatric patients with T1DM, the findings of EDIC, as mentioned above, highlight the importance of

Table 3 Screening for neuropathy in pediatric diabetes

\begin{tabular}{|c|c|c|}
\hline \multirow[t]{5}{*}{ Screening tool } & Nerve conduction velocities & $\begin{array}{l}\text { The gold standard: determines the adequacy } \\
\text { of impulse the conduction of through nerves }\end{array}$ \\
\hline & Semmes-Weinstein monofilament test & Detects pressure perception \\
\hline & Tuning forks & Detects vibration perception \\
\hline & Survey of symptoms & $\begin{array}{l}\text { Review of systems to detect new symptoms } \\
\text { such as numbness, pain, cramps, paresthesias, } \\
\text { alteration of sensation in vibration and light } \\
\text { touch }\end{array}$ \\
\hline & $\begin{array}{l}\text { Cardiovascular autonomic function } \\
\text { testing }\end{array}$ & Detects reduced heart rate variability \\
\hline Screening parameters & \multicolumn{2}{|c|}{ All modalities screen for evidence of loss of sensitivity and non-perception } \\
\hline \multirow[t]{2}{*}{ Age to initiate screening } & Type I diabetes mellitus & Starting after 5 years of disease \\
\hline & Type 2 diabetes mellitus & Starting at the time of diagnosis \\
\hline Frequency of screening & Type I diabetes mellitus: annually & Type 2 diabetes mellitus: annually \\
\hline
\end{tabular}


Table 4 Screening for hypertension in pediatric diabetes

\begin{tabular}{|c|c|c|}
\hline \multirow[t]{2}{*}{ Screening tool } & In-office blood pressure & $\begin{array}{l}\text { Static measurement of sphygmomanometer cuff } \\
\text { pressure }\end{array}$ \\
\hline & 24-hour ambulatory blood pressure & $\begin{array}{l}\text { Measures blood pressure at regular intervals } \\
\text { throughout the day }\end{array}$ \\
\hline \multirow[t]{2}{*}{ Screening parameters } & High-normal blood pressure & $\begin{array}{l}\text { Findings: average systolic or diastolic blood pressure } \\
\geq 90 \text { th but }<95 \text { th percentile for age, sex, and } \\
\text { height measured on three separate days }\end{array}$ \\
\hline & Hypertension & $\begin{array}{l}\text { Findings: average systolic or diastolic blood pressure } \\
\geq 95 \text { th percentile for age, sex, and height measured } \\
\text { on three separate days }\end{array}$ \\
\hline \multirow[t]{2}{*}{ Age to initiate screening } & Type I diabetes mellitus & Starting at time of diagnosis \\
\hline & Type 2 diabetes mellitus & Starting at time of diagnosis \\
\hline Frequency of screening & Type I diabetes mellitus: every office visit & Type 2 diabetes mellitus: every office visit \\
\hline
\end{tabular}

preventative screening for future vascular complications in these children (Table 5).

Because of the increased risk conferred by both dyslipidemia and hyperglycemia for atherosclerosis, the American Diabetes Association (ADA) recommends cholesterol screening. ${ }^{6}$ For pre-pubertal children, a fasting lipid profile should be obtained on all children older than 2 years of age at the time of diagnosis and glucose control has been established, if there is a family history of hypercholesterolemia, if there is a family history of a cardiovascular event before age 55, or if such a family history is unknown. If family history is not of concern, lipid screening should occur at puberty. If a child is diagnosed after puberty, lipids should be checked at time of diagnosis. In the case of both age groups, if LDL is $<100 \mathrm{mg} / \mathrm{dL}$, a lipid profile should be obtained every 5 years. Borderline or abnormal values should be repeated for confirmation.

\section{Preventative therapy and treatment}

Along with screening, preventative therapy guidelines can help mitigate the risks of developing vascular complications. When evidence of end-organ damage becomes detectable as a result of screening, interventions can be initiated in an attempt to halt further progression of disease and salvage organ function. Because of common risk factors shared by the micro- and macro-vascular complications, many of the initial interventions will have beneficial effects on several developing complications. When end-organ damage does occur, therapies become directed to preserve the affected organ.

Table 5 Screening for dyslipidemia in pediatric diabetes

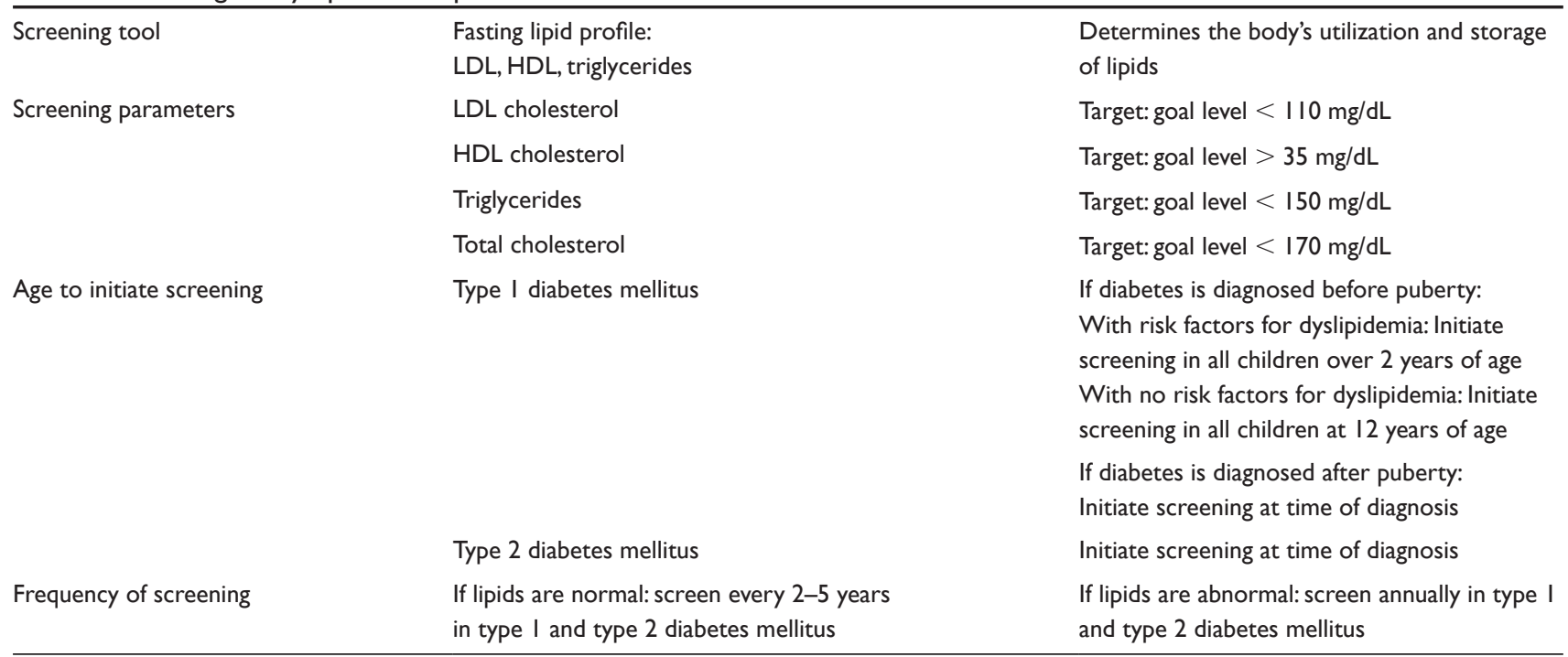

Abbreviations: HDL, high-density lipoprotein; LDL, low-density lipoprotein. 


\section{Glucose management}

With hyperglycemia as a key culprit in the micro- and macro-vascular complications of diabetes, a primary preventative intervention is maintaining euglycemia. This goal is best achieved with intensive glycemic control, which includes blood glucose monitoring throughout the day, and appropriate treatment with insulin in T1DM and the addition of other blood glucose lowering medications in T2DM. In the DCCT, intensive therapy for glycemic control was associated with excess weight gain and increased risk of hypoglycemia. Hypoglycemia is a predictable but concerning complication of intensive glycemic control. Compared to the conventional therapy group, study patients had up to a 3-fold greater risk of hypoglycemia with severe consequences such as seizures and loss of consciousness. ${ }^{1}$ To minimize the risk for hypoglycemia, recommendations in pediatric patients are to maintain $\mathrm{HbA}_{\mathrm{lc}}$ within the range of $7.5 \%$ to $8.5 \%$, depending upon age. ${ }^{62}$

Encouraging appropriate record keeping of blood glucose levels and insulin administration will also help physicians make fine adjustments in patients' insulin regimens as they grow. Logbooks are more prone to user error, however, as patients may inaccurately input data or fail to record their data. Laffel et al demonstrate that the use of meters with electronic logbooks can be associated with improvement of glycemic control as compared to paper logbooks, in both adult and pediatric populations. ${ }^{63} \mathrm{New}$ innovations such as closed-loop blood glucose monitoring and insulin delivery may help patients maintain appropriate glucose levels to avoid the consequences of hypoglycemia or hyperglycemia and the resultant vascular complications. In addition to the hyperglycemic risk factors, some non-glycemic risk factors such as smoking, weight management, dyslipidemia, and hypertension also provide areas to target preventative therapy and treatment.

\section{Smoking}

As discussed previously, smoking has been shown to exacerbate micro- and macro-vascular complications in diabetes. ${ }^{6}$ Smoking generally begins in the teenage years. It has been demonstrated that pediatric practice-based smoking cessation and prevention intervention methods have been effective in deterring smoking in adolescents. ${ }^{64}$

\section{Weight management}

Moderate weight loss in overweight adolescents has been shown to increase insulin sensitivity in the liver and skeletal muscles and improve glycemic control ${ }^{46}$ Anticipatory guidance, as well as nutrition and exercise counseling by pediatric providers, can help families make healthy decisions to prevent obesity and its complications.

\section{Dyslipidemia}

Prevention of dyslipidemia aims to protect diabetic patients from atherosclerotic disease. Initial prevention for dyslipidemia should focus on optimizing blood glucose control, decreasing total and saturated fat intake, controlling weight, and cessation of smoking if applicable. The addition of lipid-lowering agents is recommended in pediatric patients if LDL $>160$ and for patients with LDL of 130 to 159 if lifestyle and dietary interventions fail to achieve a goal $\mathrm{LDL}<100 \mathrm{mg} / \mathrm{dL}$. The ADA position statement suggests the use of HMG-CoA reductase inhibitors, which have been approved for children older than 10 years of age and have been shown to be both safe and efficacious in early trials with children with heterozygous familial hypercholesterolemia and T1DM. ${ }^{65,66}$ The 2008 American Academy of Pediatrics policy statement on cholesterol in childhood recommends treating children with hypercholesterolemia under age 8 years only in the most extreme circumstances (LDL $>500 \mathrm{mg} / \mathrm{dL}$ ) ${ }^{67}$ For this reason, the onset of puberty is a reasonable time to begin lipid lowering agents in most cases.

\section{Hypertension}

The prevention and management of hypertension may have the broadest effect on both micro- and macro-vascular complications. To manage hypertension in pediatric patients with diabetes, angiotensin converting enzyme (ACE) inhibitors, which have been shown to have beneficial microvascular protective effects, are first-line drugs of choice. Once persistent hypertension has been established by the appropriate screening modalities, nondiabetes related causes of hypertension should be excluded. Hypertension is then initially managed with increased exercise and a low- to salt-free diet. If blood pressure has not been reduced to $<90$ th percentile or $<130 / 80 \mathrm{mmHg}$ within 3 to 6 months of lifestyle intervention, pharmacologic therapy should be initiated. ACE inhibitors should be considered. This class of medication has been shown to be efficacious and safe in children from age 6 to 16 years and is FDA-approved for ages 6 years and older. ${ }^{68,69} \mathrm{ACE}$ inhibitors are contraindicated in pregnancy. In addition to the benefit of reducing hypertension, ACE inhibitors confer benefit by reducing macrovascular disease, independent of blood pressure reduction in adults with T1DM, ${ }^{70}$ 
may improve endothelial dysfunction associated with atherosclerosis, ${ }^{71}$ and may also reduce oxidative stress on the endothelium. ${ }^{72}$

Despite the wide range of potential benefits of ACEinhibitors, their therapeutic potential has been most strongly associated with prevention of renal microvascular complications. Their efficacy in this setting has been the focus of numerous clinical studies. In the Patients with Type 2 Diabetes and Microalbuminuria study which evaluated irbesartan, an angiotensin receptor blocker (ARB), urine albumin excretion was decreased by $38 \%$ and the risk of microalbuminuria was reduced by $70 \%$ compared to placebo. ${ }^{73}$ The Heart Outcomes Prevention Evaluation (HOPE) study demonstrated that in patients with diabetes, ACE inhibitors could decrease the progression to overt nephropathy by $24 \%$ compared to placebo at similar blood pressures. ${ }^{70}$ It is thought that by blocking the trophic effects of angiotensin II, these drugs help minimize the glomerular hypertrophy and mesangial matrix damage that occurs in the kidney as a result of long-term stimulation of the renin angiotensin system.

Adult patients are generally started on these antihypertensive medications with evidence of microalbuminuria. There is controversy about when to begin pediatric patients on these antihypertensive regimens, as these patients can have transient microalbuminuria during puberty that resolves afterwards. ${ }^{44}$ Starting all pediatric patients with evidence of microalbuminuria on drug therapy could lead to prolonged and unnecessary treatment. Delaying treatment, however, could result in preventable kidney damage.

While blockade of the renin-angiotensin system with ACE inhibitors and ARBs has been shown to slow the progression of nephropathy in diabetic patients with proteinuria and reduced glomerular filtration rate, a recent study by Mauer et al, the Renin-Angiotensin System Study (RASS), challenges the efficacy of ACE inhibitors and ARBs in slowing the early histologic changes of diabetic nephropathy in normotensive patients before albuminuria is present. ${ }^{74}$ The study evaluated enalapril and losartan against placebo to detect changes in mesangial fractional volume per glomerulus over a 5 -year period in patients with T1DM. They found that the change in mesangial fractional volume did not differ significantly between ACE inhibitors, ARBs, or placebo. Furthermore the 5-year cumulative incidence of microalbuminuria was found to be higher in patients on losartan than enalapril and placebo. These new data raise questions about the utility of ACE inhibitors and ARBs in early asymptomatic stages of TIDM.
Although the RASS study raises questions about the efficacy of ACE inhibitors and ARBs in pre-symptomatic nephropathy, their use was correlated with a significant reduction in the progression of retinopathy when compared with placebo in patients with T1DM. ${ }^{74}$ When compared with placebo, progression of retinopathy was reduced by $65 \%$ with the ACE inhibitor enalapril and $70 \%$ with the ARB losartan. These data suggest that despite unproven efficacy in preventing the progression of nephropathy in asymptomatic patients, ACE inhibitor and ARBs could still serve an important role in the prevention of retinopathy.

Presently, there is no official consensus about the initiation of drug treatment with ACE inhibitors and ARBs in the pediatric population with diabetes. Based on available information and risk factors, Chiarelli et al suggest treatment should be directed at pediatric patients in puberty with persistent microalbuminuria and hypertension, and in patients with microalbuminuria and additional signs of microvascular complications such as retinopathy. ${ }^{75}$ Pubertal pediatric patients with persistent microalbuminuria but normal blood pressures may be started on a trial of ACE inhibitors if modifications such as blood glucose control, reduction of protein intake, and smoking cessation have not improved the microalbuminuria. Reassessment after puberty would be warranted to avoid unnecessary prolonged treatment, as the microalbuminuria may resolve.

\section{Summary}

The macro- and microvascular complications of diabetes are driven by both glycemic and non-glycemic factors. The available evidence suggests that optimal control of blood sugar will significantly modify the risk for these factors, but even optimal glucose control may not be protective in all cases. Thus, the approach to prevention of the complications of diabetes requires a more holistic approach to body metabolism.

However, in considering the application of multiple pharmacologic approaches in the adolescent, we must also consider the impact on the young person with diabetes and his or her family. Indeed, those patients in whom we are most likely to recommend additional interventions to prevent complications are those that may already be struggling substantially with diabetes care. Adolescence, in particular, is a time when compliance with medications may be lower than at any other time in life. ${ }^{76}$ Thus, there may be greater risk in these patients for chronic hyperglycemia, dyslipidemia, and the progression of complications. Although it has not been well-studied in children, adherence with even basic diabetes 
regimens is a well-described challenge. ${ }^{77}$ As the regimens increase in complexity (more drugs, more times per day), adherence invariably drops. ${ }^{78}$ The introduction of additional pharmacotherapies may detract from the principle use of insulin or oral hypoglycemics and exacerbate hyperglycemia and risk for complications.

In addition to the challenges posed to adherence by additional medicines, older patients have also articulated that they feel like "failures" when they are prescribed an additional medication for a new problem, even if the new problem is not unexpected. ${ }^{79}$ Adolescents, even without chronic illness, may struggle with self-esteem; care must be taken by providers to help patients understand the need for additional medicines and the role of the patient on the medical team and in the treatment of their illness. Finally, these issues may also be compounded by undiagnosed depression, which further limits medication adherence. ${ }^{80-83}$ Depression in adolescents can be difficult to diagnose, particularly for the busy practitioner in an office setting that is not optimized for this screening. Nonetheless, although prescribed medical therapy can be optimized to prevent complications by the mechanisms described above, the delivery of these medicines to the patients is likely to remain a substantial challenge.

Our understanding of diabetes, its complications, and their risk factors has expanded substantially in the last 15 years. There are exciting new agents with which to optimize glycemic control and new targets to reduce glucose variability including insulin analogs, insulin pump therapy, and the promise of closed-loop insulin delivery. However, our emerging understanding suggests that even optimal glucose control may not minimize risk in all patients and that other pathways may require targeting as well. The clinical approach to diabetes is likely to continue to integrate these new findings with ever tighter goals for biochemical and physical parameters. For many of our patients, particularly those with T1DM but also those with T2DM, the diabetes diagnosis will be made in childhood and early adolescence. Prevention of complications should begin simultaneously, targeting initially optimal glucose control but expanding as needed to address these other parameters. As these goals are better understood and integrated into adult and pediatric practice, we hope practitioners will be able to provide a consistent message about treatment goals and methods across the lifetime of each individual with diabetes that may further improve adherence to these complex regimens.

\section{Disclosures}

The authors declare no conflicts of interest.

\section{References}

1. The effect of intensive treatment of diabetes on the development and progression of long-term complications in insulin-dependent diabetes mellitus. The Diabetes Control and Complications Trial Research Group. N Engl J Med. 1993;329(14):977-986.

2. Intensive blood-glucose control with sulphonylureas or insulin compared with conventional treatment and risk of complications in patients with type 2 diabetes (UKPDS 33). UK Prospective Diabetes Study (UKPDS) Group. Lancet. 1998;352(9131):837-853.

3. Arslanian S. Type 2 diabetes in children: clinical aspects and risk factors. Horm Res. 2002;57 Suppl 1:19-28.

4. Donnelly R, Emslie-Smith AM, Gardner ID, Morris AD. ABC of arterial and venous disease: vascular complications of diabetes. $B M J$. 2000;320(7241):1062-1066.

5. Nathan DM. Long-term complications of diabetes mellitus. $N$ Engl $J$ Med. 1993;328(23):1676-1685.

6. Bogdanovic R. Diabetic nephropathy in children and adolescents. Pediatr Nephrol. 2008;23(4):507-525.

7. Frank RN. Diabetic retinopathy. N Engl J Med. 2004;350(1):48-58.

8. Lueder GT, Pradhan S, White NH. Risk of retinopathy in children with type 1 diabetes mellitus before 2 years of age. Am J Ophthalmol. 2005;140(5):930-931.

9. Trotta D, Verrotti A, Salladini C, Chiarelli F. Diabetic neuropathy in children and adolescents. Pediatr Diabetes. 2004;5(1):44-57.

10. Deckert T, Poulsen JE, Larsen M. Prognosis of diabetics with diabetes onset before the age of thirty-one. II. Factors influencing the prognosis. Diabetologia. 1978;14(6):371-377.

11. Garcia MJ, McNamara PM, Gordon T, Kannel WB. Morbidity and mortality in diabetics in the Framingham population. Sixteen year follow-up study. Diabetes. 1974;23(2):105-111.

12. Fuller JH, Shipley MJ, Rose G, Jarrett RJ, Keen H. Mortality from coronary heart disease and stroke in relation to degree of glycaemia: the Whitehall study. Br Med J (Clin Res Ed). 1983;287(6396): 867-870.

13. Krolewski AS, Kosinski EJ, Warram JH, et al. Magnitude and determinants of coronary artery disease in juvenile-onset, insulin-dependent diabetes mellitus. Am J Cardiol. 1987;59(8):750-755.

14. Laing SP, Swerdlow AJ, Carpenter LM, et al. Mortality from cerebrovascular disease in a cohort of 23000 patients with insulin-treated diabetes. Stroke. 2003;34(2):418-421.

15. Greenland P, Abrams J, Aurigemma GP, et al. Prevention Conference V: Beyond secondary prevention: identifying the high-risk patient for primary prevention: noninvasive tests of atherosclerotic burden: Writing Group III. Circulation. 2000;101(1):E16-E22.

16. Jarvisalo MJ, Putto-Laurila A, Jartti L, et al. Carotid artery intimamedia thickness in children with type 1 diabetes. Diabetes. 2002;51(2): 493-498.

17. Krantz JS, Mack WJ, Hodis HN, Liu CR, Liu CH, Kaufman FR. Early onset of subclinical atherosclerosis in young persons with type 1 diabetes. J Pediatr. 2004;145(4):452-457.

18. O'Leary DH, Polak JF, Kronmal RA, Manolio TA, Burke GL, Wolfson SK Jr. Carotid-artery intima and media thickness as a risk factor for myocardial infarction and stroke in older adults. Cardiovascular Health Study Collaborative Research Group. N Engl J Med. 1999;340(1):14-22.

19. Skyler JS. Diabetic complications. The importance of glucose control. Endocrinol Metab Clin North Am. 1996 Jun;25(2):243-254.

20. Lueder GT, Silverstein J. Screening for retinopathy in the pediatric patient with type 1 diabetes mellitus. Pediatrics. 2005;116(1): 270-273.

21. Nathan DM, Lachin J, Cleary P, et al. Intensive diabetes therapy and carotid intima-media thickness in type 1 diabetes mellitus. $N$ Engl $J$ Med. 2003;348(23):2294-2303.

22. Nathan DM, Cleary PA, Backlund JY, et al. Intensive diabetes treatment and cardiovascular disease in patients with type 1 diabetes. $N$ Engl $J$ Med. 2005;353(25):2643-2653. 
23. Shankar A, Klein R, Klein BE, Moss SE. Association between glycosylated hemoglobin level and cardiovascular and all-cause mortality in type 1 diabetes. Am J Epidemiol. 2007;166(4):393-402.

24. Selvin E, Marinopoulos S, Berkenblit G, et al. Meta-analysis: glycosylated hemoglobin and cardiovascular disease in diabetes mellitus. Ann Intern Med. 2004;141(6):421-431.

25. Olson JC, Erbey JR, Forrest KY, Williams K, Becker DJ, Orchard TJ. Glycemia (or, in women, estimated glucose disposal rate) predict lower extremity arterial disease events in type 1 diabetes. Metabolism. 2002;51(2):248-254.

26. Pambianco G, Costacou T, Ellis D, Becker DJ, Klein R, Orchard TJ. The 30-year natural history of type 1 diabetes complications: the Pittsburgh Epidemiology of Diabetes Complications Study experience. Diabetes. 2006;55(5):1463-1469.

27. Orchard TJ, Olson JC, Erbey JR, et al; Insulin resistance-related factors, but not glycemia, predict coronary artery disease in type 1 diabetes: 10-year follow-up data from the Pittsburgh Epidemiology of Diabetes Complications Study. Diabetes Care. 2003;26(5):1374-1379.

28. Soedamah-Muthu SS, Chaturvedi N, Toeller M, et al; Risk factors for coronary heart disease in type 1 diabetic patients in Europe: the EURODIAB Prospective Complications Study. Diabetes Care. 2004;27(2):530-537.

29. Davis TM, Bruce DG, Davis WA; Predictors of first stroke in Type 1 diabetes: The Fremantle Diabetes Study. Diabet Med. 2005;22(5): 551-553.

30. Effect of intensive diabetes management on macrovascular events and risk factors in the Diabetes Control and Complications Trial. Am J Cardiol. 1995;75(14):894-903.

31. Lurbe E, Redon J, Kesani A, et al. Increase in nocturnal blood pressure and progression to microalbuminuria in type 1 diabetes. $N$ Engl $\mathrm{J} \mathrm{Med}$. 2002;347(11):797-805.

32. Remuzzi G, Schieppati A, Ruggenenti P. Clinical practice. Nephropathy in patients with type 2 diabetes. $N$ Engl J Med. 2002;346(15): $1145-1151$

33. Tight blood pressure control and risk of macrovascular and microvascular complications in type 2 diabetes: UKPDS 38. UK Prospective Diabetes Study Group. BMJ. 1998;317(7160):703-713.

34. Testa MA, Puklin JE, Sherwin RS, Simonson DC. Clinical predictors of retinopathy and its progression in patients with type I diabetes during CSII or conventional insulin treatment. Diabetes. 1985;34 Suppl 3: 61-68.

35. Chase HP, Garg SK, Jackson WE, et al. Blood pressure and retinopathy in type I diabetes. Ophthalmology. 1990;97(2):155-159.

36. Forrest KY, Maser RE, Pambianco G, Becker DJ, Orchard TJ. Hypertension as a risk factor for diabetic neuropathy: a prospective study. Diabetes. 1997;46(4):665-670.

37. Orchard TJ, Forrest KY, Kuller LH, Becker DJ; Lipid and blood pressure treatment goals for type 1 diabetes: 10-year incidence data from the Pittsburgh Epidemiology of Diabetes Complications Study. Diabetes Care. 2001;24(6):1053-1059.

38. Witte DR, Tesfaye S, Chaturvedi N, Eaton SE, Kempler P, Fuller JH. Risk factors for cardiac autonomic neuropathy in type 1 diabetes mellitus. Diabetologia. 2005;48(1):164-171.

39. Kempler P, Tesfaye S, Chaturvedi N, et al; Blood pressure response to standing in the diagnosis of autonomic neuropathy: the EURODIAB IDDM Complications Study. Arch Physiol Biochem. 2001;109(3):215-222.

40. Kempler P, Tesfaye S, Chaturvedi N, et al. Autonomic neuropathy is associated with increased cardiovascular risk factors: the EURODIAB IDDM Complications Study. Diabet Med. 2002;19(11):900-909.

41. Hofer SE, Rosenbauer J, Grulich-Henn J, Naeke A, Frohlich-Reiterer E, Holl RW. Smoking and metabolic control in adolescents with type 1 diabetes. J Pediatr. 2009;154(1):20-23 e21.

42. Houston TK, Person SD, Pletcher MJ, Liu K, Iribarren C, Kiefe CI; Active and passive smoking and development of glucose intolerance among young adults in a prospective cohort: CARDIA study. BMJ. 2006;332(7549):1064-1069.
43. Chiodera P, Volpi R, Capretti L, et al. Abnormal effect of cigarette smoking on pituitary hormone secretions in insulin-dependent diabetes mellitus. Clin Endocrinol (Oxf). 1997;46(3):351-357.

44. Sinha RN, Patrick AW, Richardson L, Wallymahmed M, MacFarlane IA. A six-year follow-up study of smoking habits and microvascular complications in young adults with type 1 diabetes. Postgrad Med J. 1997;73(859):293-294.

45. Maahs DM, Maniatis AK, Nadeau K, Wadwa RP, McFann K, Klingensmith GJ. Total cholesterol and high-density lipoprotein levels in pediatric subjects with type 1 diabetes mellitus. $J$ Pediatr. 2005;147(4):544-546.

46. Vitola BE, Deivanayagam S, Stein RI, et al. Weight loss reduces liver fat and improves hepatic and skeletal muscle insulin sensitivity in obese adolescents. Obesity (Silver Spring). 2009;17(9):1744-1748.

47. Newfield RS, Cohen D, Capparelli EV, Shragg P. Rapid weight gain in children soon after diagnosis of type 1 diabetes: is there room for concern? Pediatr Diabetes. 2009;10(5):310-315.

48. August GP, Caprio S, Fennoy I, et al. Prevention and treatment of pediatric obesity: an endocrine society clinical practice guideline based on expert opinion. J Clin Endocrinol Metab. 2008 Dec;93(12): 4576-4599.

49. Rogers DG, White NH, Shalwitz RA, Palmberg P, Smith ME, Santiago JV. The effect of puberty on the development of early diabetic microvascular disease in insulin-dependent diabetes. Diabetes Res Clin Pract. 1987;3(1):39-44.

50. Klein R, Klein BE, Moss SE. Epidemiology of proliferative diabetic retinopathy. Diabetes Care. 1992;15(12):1875-1891.

51. Riihimaa PH, Suominen K, Tolonen U, Jantti V, Knip M, Tapanainen P. Peripheral nerve function is increasingly impaired during puberty in adolescents with type 1 diabetes. Diabetes Care. 2001;24(6): 1087-1092.

52. Quinn M, Angelico MC, Warram JH, Krolewski AS. Familial factors determine the development of diabetic nephropathy in patients with IDDM. Diabetologia. 1996;39(8):940-945.

53. Marso SP, Hiatt WR. Peripheral arterial disease in patients with diabetes. J Am Coll Cardiol. 2006;47(5):921-929.

54. Marso SP, Mak KH, Topol EJ. Diabetes mellitus: biological determinants of atherosclerosis and restenosis. Semin Interv Cardiol. 1999;4(3): 129-143.

55. Wagenknecht LE, Bowden DW, Carr JJ, Langefeld CD, Freedman BI, Rich SS. Familial aggregation of coronary artery calcium in families with type 2 diabetes. Diabetes. 2001;50(4):861-866.

56. Satko SG, Freedman BI. The familial clustering of renal disease and related phenotypes. Med Clin North Am. 2005;89(3):447-456.

57. Wang Q. Molecular genetics of coronary artery disease. Curr Opin Cardiol. 2005;20(3):182-188

58. Brownlee M. Biochemistry and molecular cell biology of diabetic complications. Nature. 2001;414(6865):813-820.

59. Miller CD, Phillips LS, Tate MK, et al. Meeting American Diabetes Association guidelines in endocrinologist practice. Diabetes Care. 2000;23(4):444-448.

60. Stolar MW. Clinical management of the NIDDM patient. Impact of the American Diabetes Association practice guidelines, 1985-1993. Endocrine Fellows Foundation Study Group. Diabetes Care. 1995;18(5): 701-707.

61. Nelson D, Mah JK, Adams C, et al. Comparison of conventional and non-invasive techniques for the early identification of diabetic neuropathy in children and adolescents with type 1 diabetes. Pediatr Diabetes. 2006;7(6):305-310.

62. Silverstein J, Klingensmith G, Copeland K, et al. Care of children and adolescents with type 1 diabetes: a statement of the American Diabetes Association. Diabetes Care. 2005;28(1):186-212.

63. Laffel LM, Hsu WC, McGill JB, Meneghini L, Volkening LK. Continued use of an integrated meter with electronic logbook maintains improvements in glycemic control beyond a randomized, controlled trial. Diabetes Technol Ther. 2007;9(3):254-264. 
64. Pbert L, Flint AJ, Fletcher KE, Young MH, Druker S, DiFranza JR. Effect of a pediatric practice-based smoking prevention and cessation intervention for adolescents: a randomized, controlled trial. Pediatrics. 2008;121(4):e738-e747.

65. de Jongh S, Ose L, Szamosi T, et al. Efficacy and safety of statin therapy in children with familial hypercholesterolemia: a randomized, double-blind, placebo-controlled trial with simvastatin. Circulation. 2002;106(17):2231-2237.

66. Haller MJ, Stein JM, Shuster JJ, et al. Pediatric Atorvastatin in Diabetes Trial (PADIT): a pilot study to determine the effect of atorvastatin on arterial stiffness and endothelial function in children with type 1 diabetes mellitus. J Pediatr Endocrinol Metab. 2009;22(1):65-68.

67. Daniels SR, Greer FR. Lipid screening and cardiovascular health in childhood. Pediatrics. 2008;122(1):198-208.

68. Wells T, Frame V, Soffer B, et al. A double-blind, placebo-controlled, dose-response study of the effectiveness and safety of enalapril for children with hypertension. J Clin Pharmacol. 2002;42(8):870-880.

69. Soffer B, Zhang Z, Miller K, Vogt BA, Shahinfar S. A double-blind, placebo-controlled, dose-response study of the effectiveness and safety of lisinopril for children with hypertension. Am J Hypertens. 2003;16(10):795-800.

70. Effects of ramipril on cardiovascular and microvascular outcomes in people with diabetes mellitus: results of the HOPE study and MICRO-HOPE substudy. Heart Outcomes Prevention Evaluation Study Investigators. Lancet. 2000;355(9200):253-259.

71. Arcaro G, Zenere BM, Saggiani F, et al. ACE inhibitors improve endothelial function in type 1 diabetic patients with normal arterial pressure and microalbuminuria. Diabetes Care. 1999;22(9):1536-1542.

72. Ceriello A, Piconi L, Esposito K, Giugliano D. Telmisartan shows an equivalent effect of vitamin $\mathrm{C}$ in further improving endothelial dysfunction after glycemia normalization in type 1 diabetes. Diabetes Care. 2007;30(7):1694-1698.
73. Ismail N, Becker B, Strzelczyk P, Ritz E. Renal disease and hypertension in non-insulin-dependent diabetes mellitus. Kidney Int. 1999; 55(1):1-28.

74. Mauer M, Zinman B, Gardiner R, et al. Renal and retinal effects of enalapril and losartan in type 1 diabetes. $N$ Engl J Med. 2009;361(1): 40-51.

75. Chiarelli F, Trotta D, Verrotti A, Mohn A. Treatment of hypertension and microalbuminuria in children and adolescents with type 1 diabetes mellitus. Pediatr Diabetes. 2002;3(2):113-124.

76. Morris AD, Boyle DI, MacAlpine R, et al. The diabetes audit and research in Tayside Scotland (DARTS) study: electronic record linkage to create a diabetes register. DARTS/MEMO Collaboration. BMJ. 1997;315(7107):524-528.

77. Meece J. Dispelling myths and removing barriers about insulin in type 2 diabetes. Diabetes Educ. 2006;32(1 Suppl):9S-18S.

78. Paes AH, Bakker A, Soe-Agnie CJ. Impact of dosage frequency on patient compliance. Diabetes Care. 1997;20(10):1512-1517.

79. Polonsky WH, Fisher L, Guzman S, Villa-Caballero L, Edelman SV. Psychological insulin resistance in patients with type 2 diabetes: the scope of the problem. Diabetes Care. 2005;28(10):2543-2545.

80. Ciechanowski PS, Katon WJ, Russo JE. Depression and diabetes: impact of depressive symptoms on adherence, function, and costs Arch Intern Med. 2000;160(21):3278-3285.

81. Ciechanowski PS, Katon WJ, Russo JE, Hirsch IB. The relationship of depressive symptoms to symptom reporting, self-care and glucose control in diabetes. Gen Hosp Psychiatry. 2003;25(4):246-252.

82. Rubin RR, Ciechanowski P, Egede LE, Lin EH, Lustman PJ. Recognizing and treating depression in patients with diabetes. Curr Diab Rep. 2004;4(2):119-125.

83. Katon WJ, Von Korff M, Lin EH, et al. The Pathways Study: a randomized trial of collaborative care in patients with diabetes and depression. Arch Gen Psychiatry. 2004;61(10):1042-1049.
Vascular Health and Risk Management

\section{Publish your work in this journal}

Vascular Health and Risk Management is an international, peerreviewed journal of therapeutics and risk management, focusing on concise rapid reporting of clinical studies on the processes involved in the maintenance of vascular health; the monitoring, prevention and treatment of vascular disease and its sequelae; and the involvement of

\section{Dovepress}

metabolic disorders, particularly diabetes. This journal is indexed on PubMed Central and MedLine. The manuscript management system is completely online and includes a very quick and fair peer-review system, which is all easy to use. Visit http://www.dovepress.com/ testimonials.php to read real quotes from published authors 